\title{
Storage-dependent effects of oregano essential oil on lipid peroxidation and total antioxidant capacity in the grapeseed oil
}

\author{
Maryna Opryshko ${ }^{1}$, Halyna Tkachenko ${ }^{2 *}$, Natalia Kurhaluk ${ }^{2}$, Lyudmyla Buyun ${ }^{1}$, \\ Myroslava Maryniuk ${ }^{1}$, Oleksandr Gyrenko ${ }^{1}$ \\ ${ }^{1}$ M.M. Gryshko National Botanic Garden, National Academy of Science of Ukraine, Kyiv, Ukraine \\ ${ }^{2}$ Institute of Biology and Earth Sciences, Pomeranian University in Słupsk, Poland \\ ORCID \\ Halyna Tkachenko: https://orcid.org/0000-0003-3951-9005 \\ Natalia Kurhaluk: https://orcid.org/0000-0002-4669-1092 \\ Lyudmyla Buyun: https://orcid.org/0000-0002-9158-6451
}

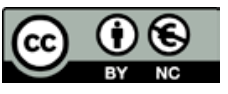

Article Details:

Received: $\quad$ 2021-07-11

Accepted: 2021-08-27

Available online: 2021-11-30

DOI: https://doi.org/10.15414/ainhlq.2021.0026

\begin{abstract}
Natural preservatives such as essential oils can be used as alternatives to chemical additives which could extend the shelf life of various food products. The knowledge about them can have important economic responsiveness by a decrease of spoilage-induced losses. The purpose of the current study was to investigate the content of 2-thiobarbituric acid reactive substances (TBARS) and total antioxidant capacity (TAC) in the grapeseed oil with the use of a commercial oregano essential oil (Etja, Elblag, Poland) as an antioxidant agent by monitoring the lipid peroxidation and antioxidant capacity. The effect of the oregano essential oil on the oxidative stability of the grapeseed oil was evaluated throughout 120 days of storage. The current results demonstrated that administration of oregano essential oil, exhibiting free radical scavenging activity determined by TBARS assay, exerts beneficial effects on preventing lipid peroxidation in grapeseed oil by limiting the TBARS levels and simultaneously increase of total antioxidant capacity, especially at 15-60 days of storage. At 60-120-day periods of storage, the TBARS levels were significantly lowered from control samples. The highest level of total antioxidant capacity was observed on 30-days compared to the control samples. Thus, edible adding containing essential oils have potential application in the plant oils to maintain their characteristics during the different shelf life.
\end{abstract}

Keywords: Grapeseed oil, oregano essential oil, 2-thiobarbituric acid reactive substances, lipid peroxidation, total antioxidant capacity, storage

\section{Introduction}

Oregano is known as the name used to refer to a great variety of plants, at least 61 species, and 17 genera belonging to six different botanical families. Verbenaceae and Lamiaceae are the most conspicuous families. Within the Lamiaceae family are the plants belonging to the genera Origanum and Hedeoma; while the genera Lippia and Lantana belong to the Verbenaceae family. The other families are Rubiaceae, Apiaceae, and Asteraceae (Kintzios, 2012; Baser and Buchbauer, 2015; Leyva-López et al., 2017). Hedeoma patens, Lippia graveolens, Lippia palmeri, Lippia alba, Origanum dictamnus, Origanum hirtum, Origanum onites, Origanum vulgare are some plants of oregano

\footnotetext{
*Corresponding Author: Halyna Tkachenko, Institute of Biology and Earth Sciences, Pomeranian University in Słupsk, Arciszewski str. 22b, 76-200 Słupsk, Poland

$\triangle$ tkachenko@apsl.edu.pl
} 
species producing essential oils (EOs) (Economou et al., 2011; Baser and Buchbauer, 2015; Leyva-López et al., 2016, 2017).

Oregano is a plant that has been used as a food seasoning since ancient times. The main compounds identified in the different oregano EOs are carvacrol and thymol, which are responsible for the characteristic odor, antimicrobial, and antioxidant activity (RodriguezGarcia et al., 2016). However, their content may vary according to the species, harvesting season, and geographical sources. For example, the qualitative and quantitative composition of EO compounds of European Origanum vulgare L. was analysed by Lukas and co-workers (2015). The content of EO compounds of European $O$. vulgare ranged between 0.03 and $4.6 \%$. The monoterpenes were primarily made up of sabinene, myrcene, $p$-cymene, 1,8-cineole, $\beta$-ocimene, $\gamma$-terpinene, sabinene hydrate, linalool, $\alpha$-terpineol, carvacrol methyl ether, linalyl acetate, thymol, and carvacrol. Among the sesquiterpenes $\beta$-caryophyllene, germacrene $\mathrm{D}$, germacrene $\mathrm{D}$-4-ol, spathulenol, caryophyllene oxide, and oplopanone were often present in higher amounts. According to the proportions of cymyl-compounds, sabinyl-compounds, and the acyclic linalool/linalyl acetate, three different main monoterpene chemotypes were defined. The cymyl- and the acyclic pathway were usually active in plants from the Mediterranean climate whereas an active sabinyl-pathway was a characteristic of plants from the Continental climate (Lukas et al., 2015). On the other hand, the comparative results of $O$. vulgare collected from four different regions in the Kumaon region (Uttarakhand, India) also showed differences in the chemical constituents of the EOs (Pande et al., 2012). The oil of $O$. vulgare collected from Dhoulchina and Champawat (chemotype I) shows $p$-cymene (6.7-9.8 \%), $\gamma$-terpinene (12.4-14.0\%), thymol (29.7-35.1\%), and carvacrol (12.4-20.9\%) as major constituents while the oil from Kilbury and Rushi village (chemotype II) shows linalool (6.7-9.7 \%), bornyl acetate (12.6-16.8 \%), $\beta$-caryophyllene $(10.5-13.8 \%)$ and germacrene D (6.3-11.3 \%) as the major constituents (Pande et al., 2012).

The study of Verma et al. (2012) also showed that the plant stage had a significant effect on the EO content and composition of $O$. vulgare. A total of 38 constituents, representing 97.4-99.7 \% of the total oil composition, were identified. Major components of oils were thymol (40.9-63.4\%), $p$-cymene, (5.1-25.9\%), $\gamma$-terpinene (1.4-20.1\%), bicyclogermacrene (0.2-6.1\%), terpinen-4-ol (3.5-5.9 \%), $\alpha$-pinene (1.6-3.1 \%), 1-octen-3-ol (1.4-2.7\%), $\alpha$-terpinene (1.0-2.2 \%), carvacrol $(<0.1-2.1 \%)$, $\beta$-caryophyllene (0.5-2.0\%) and $\beta$-myrcene (1.2-1.9\%). Thymol, terpinen-4-ol, 3 -octanol, $\alpha$-pinene, $\beta$-pinene, 1,8-cineole, $\alpha$-cubebene, and (E)- $\beta$-ocimene were observed to be higher during the full flowering stage (Verma et al., 2012). These substances as antibacterial agents make the cell membrane permeable due to its impregnation in the hydrophobic domains, this effect is higher against gram-positive bacteria (Rodriguez-Garcia et al., 2016; Sakkas et al., 2017).

Several studies have been conducted to determine and evaluate the biological properties of oregano EO. Most of the studies are focused on antimicrobial activity, such as antifungal, bactericidal, and antiviral (LeyvaLópez et al., 2017). Also, recently other properties of EO compounds have come to the attention of researchers. The oregano EO can be used as alternatives to chemical additives which could extend the food products' shelf life. The knowledge about them can have important economic feedback by reducing losses attributed to spoilage and by allowing the products to reach distant and new markets (Pavelková et al., 2014). The oregano EO has antioxidant properties effective in retarding the process of lipid peroxidation in fatty foods and scavenging free radicals (Rodriguez-Garcia et al., 2016).

Therefore, it is interesting to study the progress of lipid oxidation in plant oils with the addition of oregano EO as an antioxidant. We hypothesized that oregano EO would inhibit or reduce the level of lipid oxidation in plant oils due to the antioxidative properties of the EO. Also, contents of the lipid peroxidation marker in the plant oils were monitored during the storage period to investigate if lipid oxidation can have effects on the fate of bioactive compounds in the plant oils during storage. Thus, the purpose of the current study was to investigate the content of 2-thiobarbituric acid reactive substances (TBARS) and total antioxidant capacity (TAC) in the grapeseed oil with the use of a commercial oregano EO (Etja, Elblag, Poland) as an antioxidant agent by monitoring the lipid peroxidation for 120 -days storage period.

\section{Materials and methodology}

\section{Preparation of samples}

The grapeseed oil was obtained from a local shop. Grapeseed Oil (Monini, Italy) is a product that contains polyunsaturated fatty acids. The energy value of $100 \mathrm{~mL}$ is $3404 \mathrm{~kJ} / 828 \mathrm{kcal}$, fat $92 \mathrm{~g}$, including $11 \mathrm{~g}$ saturated fatty acids, $24 \mathrm{~g}$ monounsaturated fatty acids, and $57 \mathrm{~g}$ polyunsaturated fatty acids. The grapeseed oil sample ( $5 \mathrm{~mL}$ ) was incubated with $0.1 \mathrm{~mL}$ of oregano EO (Etja, 
Elblag, Poland) (final concentration was $20 \mu \mathrm{g} / \mathrm{mL}$ ) at $25{ }^{\circ} \mathrm{C}$ for 240 days. This reaction mixture was shaken gently while being incubated for a fixed interval at $25^{\circ} \mathrm{C}$. Samples were removed at $0,8,15,30,60$, and 120 days of storage for analysis. The grapeseed oil was used as the control samples.

\section{Assay of 2-thiobarbituric acid reactive substances (TBARS)}

Lipid oxidation was evaluated by TBARS according to the method described by Kamyshnikov (2004) with some modifications. Briefly, $0.1 \mathrm{~mL}$ of sample was added with $2 \mathrm{~mL}$ of distilled water, $1 \mathrm{~mL}$ of $20 \%$ trichloroacetic acid (TCA), and $1 \mathrm{~mL}$ of 2-thiobarbituric acid (TBA) in a test tube and, the tube content was immediately vortexed. Following water bath treatment at $100{ }^{\circ} \mathrm{C}$ for $15 \mathrm{~min}$, the tube content was cooled rapidly down to room temperature and centrifuged at $1000 \times \mathrm{g}$ for $10 \mathrm{~min}$. Then, absorbance was measured at $540 \mathrm{~nm}$ with a spectrophotometer (Specol 11, Carl Zeiss Jena, Germany) against blind $(2.1 \mathrm{~mL}$ distilled water and $2 \mathrm{~mL}$ TCA-TBA solution). TBARS were calculated as $\mu$ moles malonic dialdehyde (MDA) per $\mathrm{L}$ of the sample.

\section{Measurement of total antioxidant capacity (TAC)}

The TAC level in the samples was estimated by measuring the 2-thiobarbituric acid reactive substances (TBARS) level after Tween 80 oxidation. This level was determined spectrophotometrically at $532 \mathrm{~nm}$ (Galaktionova et al., 1998). Sample inhibits the $\mathrm{Fe}^{2+} /$ ascorbate-induced oxidation of Tween 80 , resulting in a decrease in the TBARS level. The level of TAC in the sample (\%) was calculated concerning the absorbance of the blank sample.

\section{Statistical analysis}

Results are expressed as the mean. All variables were tested for normal distribution using the KolmogorovSmirnov test $(\mathrm{p}>0.05)$. Significance of differences in the lipid peroxidation biomarker in the samples (significance level at $\mathrm{p}<0.05$ ) was examined using the Mann-Whitney test according to Zar (1999). All statistical calculations were performed on separate data from each sample with STATISTICA 8.0 software (StatSoft, Krakow, Poland).

\section{Results and discussion}

Lipid oxidation is a very complex process initiated by peroxidation of the unsaturated fatty acid in phospholipid membranes to form primary oxidation products, hydroperoxides. The hydroperoxides decompose into further secondary oxidation products, such as aldehydes, ketones, alkenes, and alcohols that cause off-flavours and odors in food products (Kumar et al., 2015). The effect of the oregano EO on oxidative stability of the grapeseed oil was evaluated throughout 120 days of storage. The inclusion of the oregano EO

\section{TBARS}

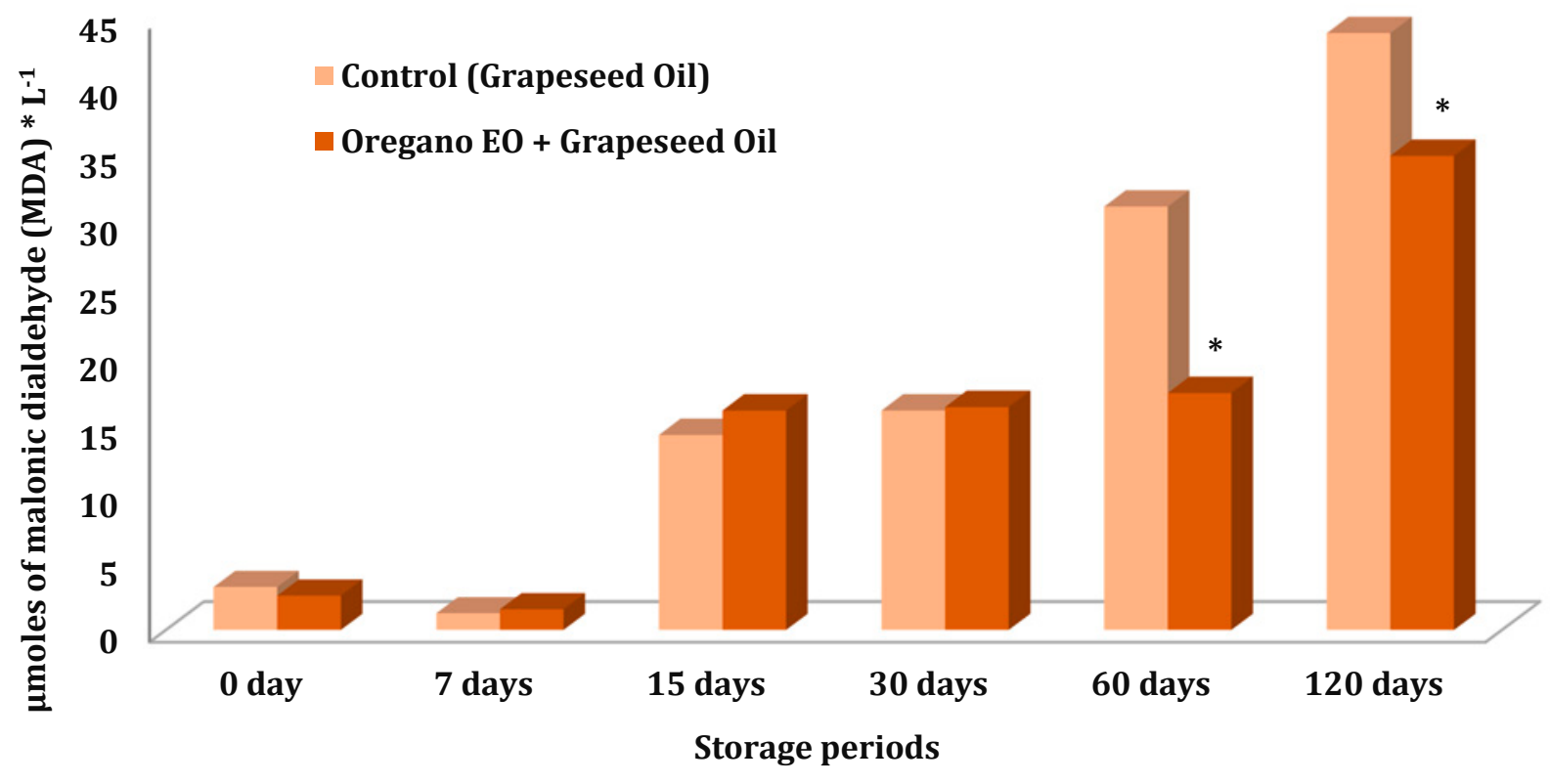

Figure 1 The effect of the addition of oregano essential oil and storage time on TBARS value (a biomarker of lipid peroxidation) in the grapeseed oil at $7,15,30,60$, and 120 days of storage

$*$ - means are significantly different $(\mathrm{p}<0.05, \mathrm{n}=6)$ 
in plant oil and storage time significantly affected TBARS values at 60 and 120 days (Figure 1). The effect of the interaction of the addition of oregano EO and storage time on TBARS value in the grapeseed oil was presented in Figure 1.

The oregano EO decreased lipid oxidation significantly $(p<0.05)$ during storage, which showed the highest decrease at 60 days (by $44 \%, \mathrm{p}<0.05$ ) and at 120 days (by $20.5 \%, p>0.05$ ) compared to the control sample. The oregano EO decreased lipid oxidation by $20 \%$ ( $p>0.05$ ) at the start of the study (0 days), but this change was non-significant. At 15 and 30 days, the TBARS values reached approximately 14.36 and $16.16 \mu \mathrm{mols} / \mathrm{L}$, corresponding to an increase in TBARS levels to 16.15 and $16.41 \mu \mathrm{mols} / \mathrm{L}$ for samples enriched by oregano EO (Figure 1). Thus, oregano EO incubated with grapeseed oil caused the maximum decrease of lipid peroxidation on 60 and 120 days.

Total antioxidant capacity (TAC) is an analyte frequently used to assess the antioxidant status of biological samples and can evaluate the antioxidant response against the free radicals produced in a given condition (Rubio et al., 2016). The effect of the addition of oregano EO and storage time on total antioxidant capacity in the grapeseed oil at $7,15,30,60$, and 120 days of storage was demonstrated in Figure 2.
Total antioxidant capacity in the grapeseed oil at 7, 15, 30 , and 60 days of storage was decreased by $6.2 \%$, $12.9 \%, 19.4 \%$, and $36.1 \%$, respectively compared to the start of the study ( 0 days). The adding of oregano EO increased the TAC level in the grapeseed oil at 15, 30 , and 60 days of storage compared to the control samples (grapeseed oil) by $17.4 \%, 30.7 \%$, and $16.2 \%$ ( $\mathrm{p}<0.05$ ), respectively (Figure 2). On 7 and 120 days, the non-significantly increase of TAC level compared to the control samples was also observed (by 9.2 and $9.3 \%, \mathrm{p}>0.05$ ) (Figure 2).

The potent antioxidant properties of oregano EOs are of potential interest to the food, cosmetic and pharmaceutical industries (Leyva-López et al., 2017). The potent antioxidant properties of oregano EOs are of potential interest to the food, cosmetic and pharmaceutical industries (Leyva-López et al., 2017). For example, the application of oregano EOs as natural preservatives is recommended in meat products, especially in chicken and fish meats. The effect of ethylenediaminetetraacetate (EDTA), oregano (Origanum vulgare), and thyme (Thymus vulgaris) oils, on the chicken breast fillets, was examined by Pavelková and co-workers (2014). The chicken breast fillets were stored under vacuum packaging (VP), at $4 \pm 0.5{ }^{\circ} \mathrm{C}$ for 18 days. There were used the following treatments of chicken breast fillets: Air-packaged (AC,

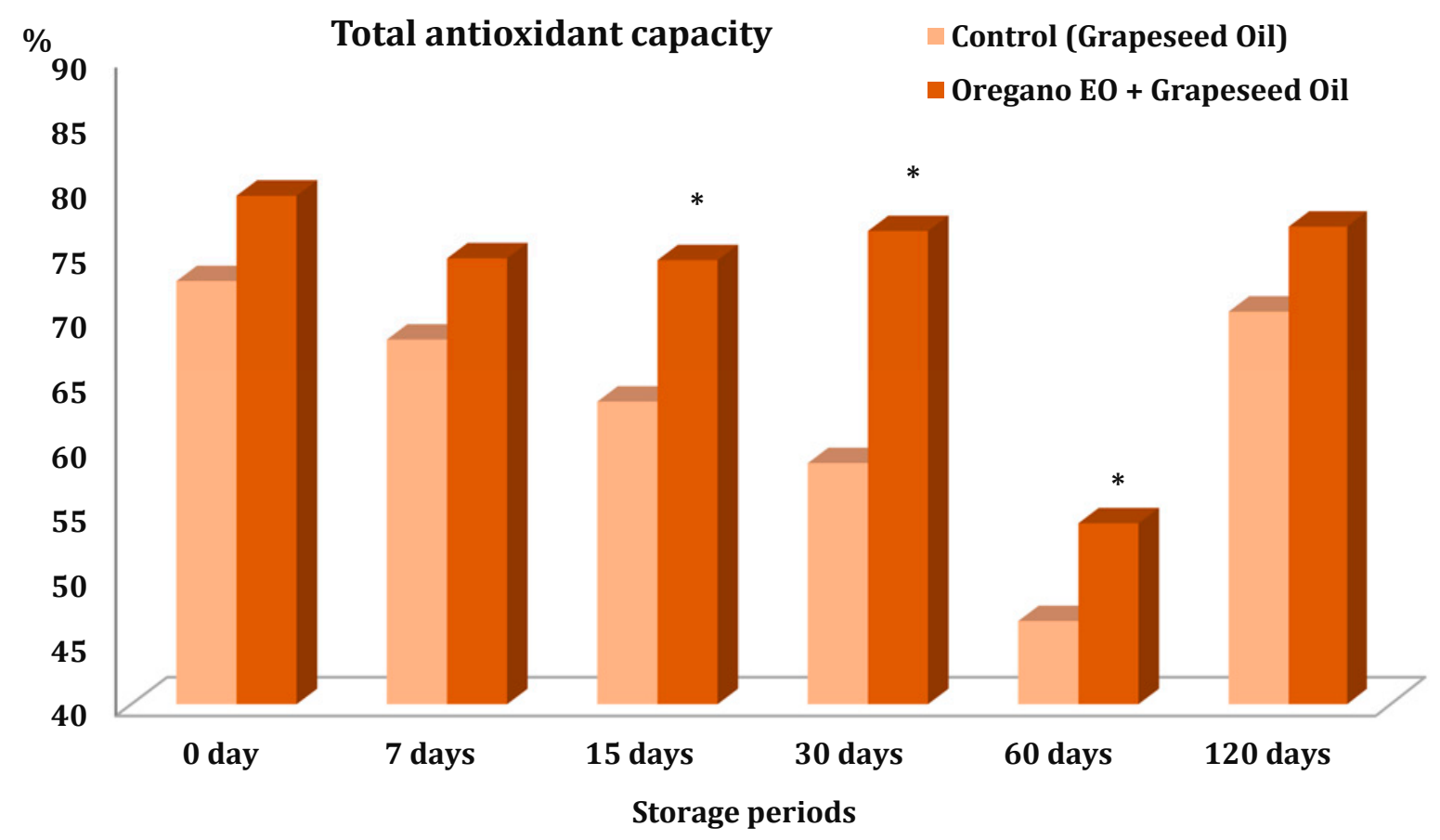

Figure 2 The effect of the addition of oregano essential oil and storage time on total antioxidant capacity (TAC, \%) in the grapeseed oil at $7,15,30,60$, and 120 days of storage

$*$ - means are significantly different $(\mathrm{p}<0.05, \mathrm{n}=6)$ 
control samples), vacuum-packaged (VPC, control samples), VP with EDTA solution $1.50 \% \mathrm{w} / \mathrm{w}$ (VPEC, control samples), VP with oregano EO $0.20 \% \mathrm{v} / \mathrm{w}$ (VP + O) and VP with thyme EO $0.20 \% \mathrm{v} / \mathrm{w},(\mathrm{VP}+\mathrm{T})$. The use of oregano, thyme EOs, and EDTA with a combination of vacuum packaging has significant effects on the reduction of all followed groups of microorganisms compared with a control group without vacuum packaging and untreated control group (Pavelková et al., 2014).

A similar study was conducted using lamb and beef meats. The effect of thyme and oregano EOs, as well as modified atmosphere packaging (MAP) in extending the shelf life of fresh lamb meat stored at $4{ }^{\circ} \mathrm{C}$, was investigated by Karabagias et al. (2011). In a preliminary experiment, thyme EO and oregano EO were used at concentrations 0.1 and $0.3 \% \mathrm{v} / \mathrm{w}$. Based primarily on the sensory analysis (odor) but also on microbiological data, the shelf life of lamb meat was 7 days for air packaged samples, 9-10 days for samples containing $0.1 \%$ of thyme EO and 21-22 days for MAP packaged samples containing $0.1 \%$ thyme EO. Tsigarida et al. (2000) reported a reduction in initial microflora of beef meat fillets by 2-3 log cfu/g with the addition of $0.8 \%$ of oregano EO with lactic acid bacteria and Listeria monocytogenes indicating the most apparent decrease in all gaseous environments. The addition of $0.8 \%$ oregano EO resulted in limited growth aerobically and survival/death of $L$. monocytogenes in MAP/VP, regardless of film permeability. These results are also in agreement with those of Skandamis and Nychas (2001) who reported an immediate suppression of TVC in minced beef meat by 1 log cfu/g when oregano E0 was added at a concentration of $1 \%$. Oregano EO delayed microbial growth and suppressed the final counts of the spoilage microorganisms. It also caused a pronounced alteration in the physicochemical properties of the minced meat.

Also, the effect of thyme and oregano EOs $(0.05 \%, \mathrm{v} / \mathrm{w})$ on the shelf life of salmon and seaweed burgers was assayed by Dolea et al. (2018). Three types of salmon and seaweed burgers were prepared: without EO, burgers with red thyme EO $(0.05 \%, \mathrm{v} / \mathrm{w})$, and burgers with oregano EO $(0.05 \%, v / w)$, which were vacuum packaged and stored at $4{ }^{\circ} \mathrm{C}$ for 17 days. Physicochemical and microbiological analyses were carried out periodically throughout storage. The addition of both EOs did not have any effect on the evolution of the $\mathrm{pH}$, the moisture content, or texture parameters. Only the thyme EO managed to slightly slow down the increase of total volatile basic nitrogen and trimethylamine nitrogen. The samples with oregano EO and especially those with thyme EO showed minor oxidation. The salmon and seaweed burgers without EOs and those which contained oregano EO showed a faster increase of mesophilic counts than those which had thyme EO, but no noticeable improvement was observed in the shelf life of the burgers with thyme EO. To improve the shelf life of the fish and seaweed burgers, it would be necessary to increase the concentration of both EOs (Dolea et al., 2018).

The effects of quince seed mucilage film (QSMF) containing oregano or thyme EOs on shelf life extension of rainbow trout (Oncorhynchus mykiss) fillets during refrigerated storage $\left(4{ }^{\circ} \mathrm{C}\right)$ were evaluated by Jouki et al. (2014) over 18 days. Films were prepared in four different concentrations of EOs, including $0,1,1.5$, and $2 \%$. The control and the wrapped fillet samples were analysed periodically for microbiological (aerobic and psychrotrophic count, Pseudomonas spp., $\mathrm{H}_{2} \mathrm{~S}$-producing bacteria, lactic acid bacteria, and Enterobacteriaceae), chemical (TBA, TVB-N, TMA-N), and sensory characteristics. Bacteria grew most quickly in trout fillets stored in air, followed by those wrapped with QSMF and the lowest counts were in wrapped samples with QSMF + $2 \%$ thyme EO. Pseudomonas spp., Enterobacteriaceae, and LAB counts were significantly lower in samples wrapped with QSMF + $2 \%$ thyme EO. The lowest TBA value was obtained in fillets wrapped in QSMF containing $2 \%$ oregano EO. The strong antioxidant activity of QSMF + $2 \%$ oregano EO was related to the composition of oregano EO. The GC analysis of EO components revealed that carvacrol (81.85\%) was the major component of oregano EO. TBA value varied for all treatments and remained lower than $2 \mathrm{mg} \mathrm{MDA} / \mathrm{kg}$ throughout storage. QSMF extended the microbial shelf life of rainbow trout fillets by 2 days, whereas the QSMF $+1 \%$ oregano EO, $\mathrm{QSMF}+1.5 \%$ oregano EO, $\mathrm{QSMF}+2 \%$ oregano EO, $\mathrm{QSMF}+1 \%$ thyme EO, QSMF + $1.5 \%$ thyme EO and $\mathrm{QSMF}+2 \%$ thyme EO resulted in a significant shelf life extension of the trout fillets by 3, 5, 9, 6, 10 and 11 days, respectively, as compared to the control samples (Jouki et al., 2014).

Badia et al. (2020) have evaluated the influence of oregano and rosemary EOs on the growth of lactic acid bacteria and the physicochemical properties of the refrigerated vacuum-packed Tuscan sausage. After the addition of $0.05 \mathrm{wt} \%$ and $0.1 \mathrm{wt} \%$ of EO to the sausage, the rosemary EO provided a higher extension of the shelf life of the sausages (approximately 3 and 5 days, respectively) than the oregano EO (approximately 1 and 3 days, respectively). After adding $0.2 \mathrm{wt} \%$ and 0.4 $w t \%$ of EO, the oregano EO resulted in a larger increase 
of the shelf life of the samples (about 8 and 14 days, respectively) when compared with the rosemary EO (about 7 to 11 days, respectively). All the treatments slowed the growth of the lactic acid bacteria but they did not change the maximum bacterial population (Badia et al., 2020).

The antioxidant effects of oregano EO and tannic acid combinations on ground chicken breast and thigh meats were studied by Al-Hijazeen etal. (2018). Six treatments, including 1) control (none added), 2) $100 \mathrm{ppm}$ oregano $\mathrm{EO}+5 \mathrm{ppm}$ tannic acid, 3) $100 \mathrm{ppm}$ oregano EO + $10 \mathrm{ppm}$ tannic acid, 4) $200 \mathrm{ppm}$ oregano EO + 5 ppm tannic acid, 5) 200 ppm oregano EO + 10 ppm tannic acid, and 6) 5 ppm butylated hydroxyanisole (BHA) for breast or $14 \mathrm{ppm}$ for thigh meat, were prepared. Thigh meat patties showed higher 2-thiobarbituric acid reactive substances (TBARS), total carbonyl, and volatiles content compared to the breast meat during storage. A combination of $200 \mathrm{ppm}$ oregano EO with $10 \mathrm{ppm}$ tannic acid showed the most significant effects ( $\mathrm{p}<0.05$ ) on TBARS, total carbonyl, and off-odor volatile formation for both breast and thigh meats. Oregano EO (200 ppm) and $10 \mathrm{ppm}$ tannic acid combination also showed positive effects on the sensory scores of chicken thigh meat. Thus, the combination of $200 \mathrm{ppm}$ oregano EO and 10 ppm tannic acid could be a good replacement for the synthetic antioxidants in-ground cooked chicken meat (Al-Hijazeen et al., 2018).

Essential oils from caraway (Carum carvi) seeds and oregano (Origanum vulgare) plants were included in dairy cow diets to study the effects on terpene composition and sensory properties of the produced milk, as well as feed consumption, production levels of milk, and methane emissions (Lejonklev et al., 2016). Two levels of EOs, 0.2 and $1.0 \mathrm{~g}$ of oil/kg of dry matter were added to the feed of lactating cows for $24 \mathrm{~d}$. No effects on feed consumption, milk production, and methane emissions were observed. The amount and composition of volatile terpenes were altered in the produced milk based on the terpene content of the EOs used, with the total amount of terpenes increasing when EOs were added to the diet. Sensory properties of the produced milk were altered as well, and milk samples from animals receiving EO treatment were perceived as having a fresher aroma and lower stored aroma and flavour (Lejonklev et al., 2016).

\section{Conclusions}

The current results demonstrated that administration of oregano EO, exhibiting free radical scavenging activity determined by TBARS assay, exerts beneficial effects on preventing lipid peroxidation in grapeseed oil by limiting the TBARS levels and simultaneously increase of total antioxidant capacity, especially at 15-60 days of storage. At 60-120-day periods of storage, the TBARS levels were significantly lowered from control samples. The highest level of total antioxidant capacity was observed on 30-days compared to the control samples. Thus, edible adding containing essential oils have potential application in the plant oils to maintain their characteristics during the different shelf life.

\section{Conflicts of interest}

The authors declare no conflict of interest.

\section{Ethical statement}

This article does not contain any studies that would require an ethical statement.

\section{Acknowledgments}

This study was carried out during the Scholarship Program supported by The Polish National Commission for UNESCO in the Institute of Biology and Earth Sciences, Pomeranian University in Słupsk (Poland). We thank The Polish National Commission for UNESCO for providing support for our study.

\section{References}

Al-Hijazeen, M., Mendonca, A., Lee, E.J., \& Ahn, D.U. (2018). Effect of oregano oil and tannic acid combinations on the quality and sensory characteristics of cooked chicken meat. Poultry Science, 97(2), 676-683. https://doi.org/10.3382/ps/pex285

Badia, V., De Oliveira, M.S.R., Polmann, G., Milkievicz, T., Galvão, A.C., \& Da Silva Robazza, W. (2020). Effect of the addition of antimicrobial oregano (Origanum vulgare) and rosemary (Rosmarinus officinalis) essential oils on lactic acid bacteria growth in refrigerated vacuum-packed Tuscan sausage. Brazilian Journal of Microbiology, 51(1), 289-301. https://doi.org/10.1007/s42770-019-00146-7

Baser, K.H.C., \& Buchbauer, G. (2015). Handbook of Essential Oils: Science, Technology, and Applications. CRC Press; Boca Raton, FL, USA.

Dolea, D., Rizo, A., Fuentes, A., Barat, J.M., \& FernándezSegovia, I. (2018). Effect of thyme and oregano essential oils on the shelf life of salmon and seaweed burgers. Food Science and Technology International, 24(5), 394403. https://doi.org/10.1177/1082013218759364

Economou, G., Panagopoulos, G., Tarantilis, P., Kalivas, D., Kotoulas, V., Travlos, I.S., Polysiou, M., \& Karamanos, A. (2011). Variability in essential oil content and composition of Origanum hirtum L., Origanum onites L., Coridothymus capitatus (L.) and Satureja thymbra 
L. populations from the Greek island Ikaria. Industrial Crops and Products, 33, 236-241.

https://doi.org/10.1016/j.indcrop.2010.10.021

Galaktionova, L.P., Molchanov, A.V., El'chaninova, S.A., \& Varshavskil̆, B.L.A. (1998). Sostoianie perekisnogo okisleniia u bol'nykh s iazvennor̆ bolezn'iu zheludka i dvenadtsatiperstnol kishki [Lipid peroxidation in patients with gastric and duodenal peptic ulcers]. [Lipid peroxidation in patients with gastric and duodenal ulcers]. Klinicheskaia Labaratornaia Diagnostika, 6, 1014 [in Russian].

Jouki, M., Yazdi, F.T., Mortazavi, S.A., Koocheki, A., \& Khazaei, N. (2014). Effect of quince seed mucilage edible films incorporated with oregano or thyme essential oil on shelf life extension of refrigerated rainbow trout fillets. International Journal of Food Microbiology, 174, 88-97. https://doi.org/10.1016/j.ijfoodmicro.2014.01.001

Kamyshnikov, V.S. (2004). A reference book on the clinic and biochemical researches and laboratory diagnostics. MEDpress-inform, Moscow.

Karabagias, I., Badeka, A., \& Kontominas, M.G. (2011). Shelf life extension of lamb meat using thyme or oregano essential oils and modified atmosphere packaging. Meat Sci., 88(1), 109-116.

https://doi.org/10.1016/j.meatsci.2010.12.010

Kintzios, S.E. (2012). 21 Oregano. In: Peter K.V., editor. Handbook of Herbs and Spices. $2^{\text {nd }}$ ed. Woodhead Publishing; Cambridge, UK, 2012. pp. 417-436.

Kumar, Y., Yadav, D.N., Ahmad, T., \& Narsaiah, K. (2015). Recent Trends in the Use of Natural Antioxidants for Meat and Meat Products. Comprehensive Reviews in Food Science and Food Safety, 14, 796-812. https://doi.org/10.1111/1541-4337.12156

Lejonklev, J., Kidmose, U., Jensen, S., Petersen, M.A., Helwing, A.L.F., Mortensen, G., Weisbjerg, M.R., \& Larsen, M.K. (2016). Short communication: Effect of oregano and caraway essential oils on the production and flavor of cow milk. J. Dairy Sci., 99(10), 7898-7903. https://doi.org/10.3168/jds.2016-10910

Leyva-López, N., Gutiérrez-Grijalva, E.P., Vazquez-Olivo, G., \& Heredia, J.B. (2017). Essential oils of oregano: Biological activity beyond their antimicrobial properties. Molecules, 22(6), 989. https://doi.org/10.3390/molecules22060989

Leyva-López, N., Nair, V., Bang, W.Y., Cisneros-Zevallos, L., \& Heredia, J.B. (2016). Protective role of terpenes and polyphenols from three species of Oregano (Lippia graveolens, Lippia palmeri and Hedeoma patens) on the suppression of lipopolysaccharide-induced inflammation in RAW 264.7 macrophage cells. J. Ethnopharmacol., 187, 302-312. https://doi.org/10.1016/j.jep.2016.04.051
Lukas, B., Schmiderer, C., \& Novak, J. (2015). Essential oil diversity of European Origanum vulgare L. (Lamiaceae). Phytochemistry, 119, 32-40. https://doi.org/10.1016/j.phytochem.2015.09.008

Pande, C., Tewari, G., Singh, S., \& Singh, C. (2012). Chemical markers in Origanum vulgare L. from Kumaon Himalayas: a chemosystematic study. Natural Product Research, 26(2), 140-145.

https://doi.org/10.1080/14786419.2010.535150

Pavelková, A., Kačániová, M., Horská, E., Rovná, K., Hleba, L., \& Petrová, J. (2014). The effect of vacuum packaging, EDTA, oregano and thyme oils on the microbiological quality of chicken's breast. Anaerobe, 29, 128-133. https://doi.org/10.1016/j.anaerobe.2013.09.002

Rodriguez-Garcia, I., Silva-Espinoza, B.A., Ortega-Ramirez, L.A., Leyva, J.M., Siddiqui, M.W., Cruz-Valenzuela, M.R., Gonzalez-Aguilar, G.A., \& Ayala-Zavala, J.F. (2016). Oregano essential oil as an antimicrobial and antioxidant additive in food products. Critical Reviews in Food Science and Nutrition, 56(10), 1717-1727. https://doi.org/10.1080/10408398.2013.800832

Rubio, C.P., Hernández-Ruiz, J., Martinez-Subiela, S., Tvarijonaviciute, A., \& Ceron, J.J. (2016). Spectrophotometric assays for total antioxidant capacity (TAC) in dog serum: an update. BMC Veterinary Research, 12(1), 166. https://doi.org/10.1186/s12917-016-0792-7

Sakkas, H., \& Papadopoulou, C. (2017). Antimicrobial activity of basil, oregano, and thyme essential oils. Journal of Microbiolog and Biotechnology, 27(3), 429-438. https://doi.org/10.4014/jmb.1608.08024

Skandamis, P.N., \& Nychas, G.J. (2001). Effect of oregano essential oil on microbiological and physico-chemical attributes of minced meat stored in air and modified atmospheres. Journal of Applied Microbiology, 91(6), 1011-1022. https://doi.org/10.1046/j.1365-2672.2001.01467.x

Tsigarida, E., Skandamis, P., \& Nychas, G.J. (2000). Behaviour of Listeria monocytogenes and autochthonous flora on meat stored under aerobic, vacuum and modified atmosphere packaging conditions with or without the presence of oregano essential oil at 5 degrees C. Journal of Applied Microbiology, 89(6), 901-909. https://doi.org/10.1046/j.1365-2672.2000.01170.x

Verma, R.S., Padalia, R.C., \& Chauhan, A. (2012). Volatile constituents of Origanum vulgare L., 'thymol' chemotype: variability in North India during plant ontogeny. Natural Product Letters, 26(14), 1358-1362. https://doi.org/10.1080/14786419.2011.602017

Zar, J.H. (1999). Biostatistical Analysis. $4^{\text {th }}$ ed., Prentice-Hall Inc., Englewood Cliffs, New Jersey. 